\title{
Positive Impacts of Social Media at Work: Job Satisfaction, Job Calling, and Facebook Use among Co-Workers
}

\author{
Brittany Hanna ${ }^{1}$, Kerk F. Ke $e^{2, *}$, and Brett W. Robertson ${ }^{3}$ \\ ${ }^{1}$ Lieberman Research Worldwide, Huntington Beach, California 92647, USA \\ ${ }^{2}$ Department of Communication Studies, Chapman University, Orange, California 92866, USA \\ ${ }^{3}$ Department of Human Communication Studies, California State University, Fullerton, California \\ 92834, USA
}

\begin{abstract}
The number of Facebook users grew rapidly since its conception. Within today's workplace, employees are increasingly connecting with each other on Facebook for interpersonal reasons. Due to sensational reports by media outlets of inappropriate social media use, many organizations are taking extreme measures about how their employees who utilize Facebook to connect with colleagues. Contrary to the negative assumptions, McAfee [1] states that social media within the workplace can promote positive dynamics. The present study uses McAfee's argument to examine if a positive connection exists between colleagues who use Facebook to connect with each other. An online survey with questions involving Facebook use with co-workers, job satisfaction, and perceived job calling was completed by employees $(N=70)$ at two high-tech companies in Northern California, USA. Results revealed that job satisfaction is positively correlated with intensity of Facebook use among co-workers. Furthermore, feeling called to one's line of work was statistically significantly higher for the group of employees who spent the most amount of time interacting on Facebook with their co-workers than the group that spent the least amount of time. These results suggest that companies could begin to explore the positive benefits of social media use within the workplace.
\end{abstract}

\section{Introduction}

It is no surprise why many people hold negative assumptions about social media use within the workplace; most related cases in the media are sensational stories about employees being fired from the jobs due to careless Facebook posts. Love [2] cites seventeen such cases where this in instance has been displayed: a waitress was fired from her job for complaining about two customers who did not leave a tip, thirteen Virgin Airlines crew members for discussing details of their job on their Facebook accounts, and many others. After having a bad day at work, it is not unusual for one to vent about their day to their family and friends. When done offline and with trusted listeners, most people are able to

* Corresponding author: kerk.kee@gmail.com 
rant without worrying about getting fired for expressing such human emotions and desire for social support [3]. However, because private social media postings are easily searchable and accessible, many people experience high levels of stress [4]. This leads to a wide assumption that it is not wise to carelessly connect with co-workers on Facebook and allow professional colleagues into one's private online space.

Even with the negative light that the media has placed on Facebook use within the workplace, some hold a more positive position. McAfee [1] boldly puts forth the argument that not only can the internal use of social media promote positive dynamics within the workplace, banning such uses can lead to missed opportunities for innovations and problem-solving. Furthermore, in a study conducted by Brandtzag et al. [4] it was found that a users' experience with Facebook expands their relationships with their friends on the website. Finding the balance between posting careless comments on Facebook, on one hand, and utilizing it for innovation communication, problem solving, and relationship building, on the other, is a delicate task for workers in the second decade of the $21^{\text {st }}$ century. Given the realization that the internal use of Facebook within an organization can promote positive outcomes, this paper sets out to investigate the connection between intensity of Facebook use, job satisfaction, and job calling among today's knowledge workers.

\section{Literature Review}

\subsection{Job Satisfaction}

The concept of job satisfaction can be understood as employees' overall attitude towards their work and work environment [5]. Job satisfaction has been conceptualized to express how someone feels about himself or herself as an individual in the context of their work, which often stems from different psychological needs experienced by the workplace environment [6-7]. The human relations movement of organizational management laid the foundation for the belief that happy and satisfied employees work harder than those who are not [8]. Therefore, job satisfaction is often regarded as a key driver of productivity in many modern organizations [7].

Among several theories of the human relations movement, Frederick Herzberg's Motivation-Hygiene Theory examines job satisfaction [8]. Proposed in the 1950's and having been modified since, Herzberg claims that there are factors that promote job satisfaction. These factors, also known as motivators, include responsibility and career advancement. Conversely, hygiene factors, which prevent someone from being dissatisfied, include environmental conditions and interpersonal relations at work. These needs are not static, but can change over time [9]. For employees to keep a positive attitude toward their work, organizations must maintain motivators and hygiene factors at a high level for their employees through various services and strategic programs. Therefore, it is common for companies to invest in ways for employees to feel more satisfied with their jobs so that productivity could be constantly promoted.

However, job satisfaction can be inter-subjective, thus influenced by social networks in organizations. Boren and Johnson found that if an employee overhears resentment-filled messages from their co-workers, such an employee is less likely to use some of the services the company provides to their employees to increase job satisfaction [10]. Malone and Hayes noted that backstabbing-type behaviors from co-workers negatively impacted the overall workplace climate [11]. These sour outcomes can decrease organizational morale. Since job satisfaction is crucial, organizations must be louder than those employees with resentment. Making their strategic programs visible might require more effort, but could 
help build job satisfaction among employees. Not everyone will remain positive about his or her work, but unsatisfied employees could negatively impact the satisfaction of other employees.

\subsection{Perceived Job Calling}

Dik and Duffy define perceived job calling as a combination of finding a career that goes along with ones sense of personal meaning, is motivated by their social values, and comes to someone in a transcendent way [12]. In addition, Duffy and Sedlacek report that $40 \%$ of people in college feel a calling for a particular line of works, while another $30 \%$ are striving to find their calling during their college years [13]. Duffy and Autin argue that the possibility of living one's job calling is not determined by education and income levels [14]. Those ranging from 'no college degree' to a 'graduate degree' reported similar results of getting to live their job calling. However, there was a difference in the perception of if someone else should try to live out their job calling; the more educated, and higher the income one reports, the more one believes that someone should live their job calling [14].

During the human relations movement of organizational management, another prominent theory that emerged was Maslow's Hierarchy of Needs [8]. Proposed in the 1940 s as a general theory and later applied to the organizational context, Maslow argues that everyone has the drive to fulfill five basic needs of physiological survival, safety, affiliation, esteem, and self-actualization in a progressive fashion. The notion of perceived job calling discussed in this paper is akin to the needs of self-actualization conceptualized by Maslow as the ability to excel and become what one is truly capable of. Selfactualization comes more easily when one feels that his/her work has personal meaning, is motivated by their social values, and comes to someone in a transcendent way.

This theory remains informative today, as having a form of monetary income is vital to human survival. While many talk about the desire of having a 'dream job,' for a vast majority of people, the need to earn an income comes from simply having a job, whether they personally enjoy the position or not. This situation is akin to simply fulfilling the physiological survival and safety needs in Maslow's theory. In the notion of having a 'dream job,' ideally people will hold a job that is of interest to them, one that allows them to fully express who they are and all that they are capable of becoming, as if being called into a particular career or field. Therefore, perceived job calling is similar to the notion of self-actualization in Maslow's model.

When people feel the sense of a job calling, and they are able to obtain a position within the scope of their calling, they feel self-actualized and more meaningful at work. If a manager recognizes employees' inherent talents and places them to a job that utilizes the talents, boredom and anxiety levels will lower [15]. Being able to find a job where you can utilize your talent is something many people attempt to acquire. Hirschi shows that the factors that lead to this feeling of meaningfulness are that people experience more work engagement, dedication, and absorption at their job [16]. These positive impacts on employees are what organizations often look for in the people they hire.

\subsection{The Role of Social Media at the Workplace}

While the use of social media to connect with co-workers generally has had a negative connotation [2], positive organizational scholarship has attempted to study the role technology can play within the workplace [17]. In recent years, social media, such as Facebook and Twitter, have become increasingly popular. As of 2015, 1.49 billion people actively use Facebook on a monthly basis [18]. The design of Facebook allows one to connect with their friends and family on a free web-based service and online platform. An 
overwhelming majority of people tend to use social media websites to keep in touch with old friends or people they have met recently [19]. Besides simply connecting with friends and family, it is becoming common to add co-workers as 'friends' on Facebook.

Some companies have experienced positive outcomes as the results of social media use within the workplace [1]. Positive communication using social media can a form of engagement for members of an organization [17]. "By engaging in dialogue with other members, sharing information, building public goods, and becoming engaged, individuals involve themselves substantively and symbolically in the sense-making activities of the organization and move closer together in the sense of a more common understanding and a greater sense of belonging to the organizational community" (p. 572) [17].

In this study, we investigate the relationships among internal use of Facebook with coworkers as well as employees' job satisfaction and perceived job calling. We recognize an opportunity to extend theories within the human relations movement to the digital age of social media. Since working adults spend majority of their waking hours at work, feeling a psychosocial connection with one's co-workers and the outcomes of such connections motivated the present study.

In a college-student context, it was found that online extroversion influenced positive satisfaction with interacting with their peers in a face-to-face context [20]. If people know more about whom they are around physically at work, uncertainty about their co-workers can be reduced [21]. Therefore, we argue that the greater the intensity an employee engages in on Facebook interacting with their co-workers, the greater the job satisfaction they experience. Furthermore, due to today's economic state, it is true that many have a job or career path for which they do not feel a strong sense of calling or enjoyment [12]. However, the more time one spends interacting with their co-workers on Facebook, the more the use of Facebook can lead to positive social affiliation with their co-workers as 'friends' on the site, leading to a sense of community at work. A sense of community at work can lead to the development of meaning about their work as a community of practice emerges [22]. Therefore, we proposed that the greater the amount of time one spends socializing with their co-workers on Facebook, the greater the sense of job calling one experiences. Below, we advance two hypotheses to be tested in this study:

$H_{1}$ : Employees' job satisfaction is correlated with their intensity of Facebook use with co-workers.

$\mathrm{H}_{2}$ : Employees' perceived job calling varies across groups of employees who spent different amounts of time on Facebook with their co-workers.

\section{Methods}

\subsection{Participants}

For this study, we contacted two high-tech companies with main offices located in Northern California, USA. After gaining access to the companies, the gatekeepers of the organizations sent out an invitation email to employees in their divisions. Company 1 yielded 31 respondents and Company 2 had 39 respondents. There was a $25 \%$ response rate for Company 1, while the percentage is unknown for Company 2 due to additional instructions Company 2's gatekeeper sent with the survey.

\subsection{Instrumentation}

The questionnaire asked participants to indicate the social media platforms (e.g., Facebook, Twitter, LinkedIn, etc.) they use to connect with their co-workers, followed by a specific 
set of questions related to their Facebook use, job satisfaction, and job calling. We adapted the Intensity of Facebook Use Scale [23-24] to measure the psychosocial attachment through the use of Facebook with friends to the work context. The adapted scale is reliable (cronbach's alpha $=0.814$ ) and included the following questions: "Facebook is part of my everyday activity with people from work (including during breaks, after work, during the weekend, etc.)"; "I am proud to tell people from work I am on Facebook"; "Facebook has become part of the daily routine in my work life (during breaks, after work, during the weekends, etc.)"; "I feel out of touch with people from work when I haven't logged onto Facebook for a day"; "I feel I am a part of the Facebook community with people from work"; "I would be sorry if Facebook was banned in my organization (including during breaks, after work, during the weekends, etc.)"; and finally we added to the adapted scale a reversed question of "I limit my engagement with people from work on Facebook in order to maintain a work-life separation". Furthermore, we also measured the approximate amount of time individuals spend on Facebook communicating and interacting with their co-workers. The question asked was "In a typical work week, approximately how much time per day (including during breaks, after work, during the weekend, etc.) do you spend on Facebook interacting with people from work?" with the response being in different time increments (i.e., less than 10 minutes, 10-30 minutes, 31 minutes to 2 hours, etc.).

For job satisfaction, questions were adapted from Brayfield and Rothe [25] and Judge et al.'s [6] validated scale. The job satisfaction scale in our survey (cronbach's alpha $=0.755$ ) included these items: "I feel fairly well satisfied with my present job"; "Most days I am enthusiastic about my work"; "Each day of work seems like it will never end" (reversed coded); "I find real enjoyment in my work"; and "I consider my job rather unpleasant" (reversed coded). To test one's total perceived job calling, the Brief Calling Scale created by Duffy, Bott, Allan, Torrey, and Dik was used [26]. The scale in our survey (cronbach's alpha $=0.859$ ) contains two Likert-type questions: "I have a calling to a particular kind of work" and "I have a good understanding of my calling as it appears to my career."

\subsection{Procedure}

We drafted a persuasive invitational email to the gatekeepers of the two organizations. This email offered the companies the option to receive the statistical results we found at the completion of this study as an incentive to participate. Once they agreed to allow their companies to participate, these gatekeepers sent a pre-crafted invitation email on behalf of the researchers to their employees and co-workers. This invitation email contained a link to an online survey, which was completed by 70 corporate workers in these two high tech companies.

\section{Analysis}

A correlation was run to test the relationship between job satisfaction and intensity of Facebook use for Hypothesis 1. A one-way ANOVA was used for Hypothesis 2 to test if employees' perceived job calling varies across three groups of employees who reported having spent different amount of time on Facebook interacting with their co-workers.

\section{Findings}

A Pearson correlation was performed to assess the relationship between job satisfaction and intensity of Facebook use to test Hypothesis 1. There was a positive correlation between the two variables, $r=0.320, n=55, p=0.017$. Hypothesis 1 was supported. 
A one-way between groups (independent groups) ANOVA was conducted to compare the mean scores of perceived job calling across three different groups of employees categorized based on the amount of time their reported to have spent on Facebook interacting with their co-workers on a daily basis. The three groups have the following different time increments: Group 1 (less than 10 minutes), Group 2 (10 to 30 minutes), and Group 3 (31 minutes to 2 hours). An ANOVA test showed that there was a statistically significant difference in job satisfaction across groups defined by the amount of time someone spends on Facebook with their co-workers, $[F(2,51)=4.824, p=.012]$.

Post hoc comparisons using the Tukey HSD test indicated that the mean score for Group $1(M=3.17, S D=.75)$ was significantly different from Group $3(M=4.56, S D=.62)$. However, Group $2(M=3.73, S D=.56)$ did not significantly differ from either Group 1 or Group 3. Given the ANOVA test result, Hypothesis 2 was supported.

\section{Discussion \& Conclusion}

The results from this study could help shift the outlook on how companies and businesses view their employees' use of Facebook between co-workers. Generally, social media gets a negative reputation for uses related to the workplace. Work-life balance, or keeping one's personal life and work life separate, is what society deems as acceptable. While that has worked for previous generations, this study suggests that, now, it is much easier for people in today's workplace to connect with their social circles via social media, including coworkers. The findings from Hypothesis 1 indicate job satisfaction is positively correlated with how intense an individual uses Facebook to connect with their co-workers. This finding suggests that organizations should look into potentially promoting the use of Facebook within the workplace. While it might seem unconventional for companies to embrace their employees using Facebook, it could be an important strategy to success for a company that is yet to be fully tapped.

Hypothesis 2 revealed that the more time someone spent on Facebook interacting with their co-workers, the more they felt a sense of calling for their job. This finding could also be the result that these workers already feel like having something (e.g., a sense of job calling for their work) in common, therefore, they use Facebook to interact with each other with a greater degree of intensity. Connecting outside of work on a website might have provided an opportunity for these workers to further share their common interests in their line of work. Furthermore, it might also be possible that a greater desire to connect with one's co-workers comes from having other interests in common other than just work alone.

A limitation to this study is the small sample size. For future research, a larger sample size would help yield more conclusive results. It would also be interesting to investigate companies outside of a technology-based industry. It is possible these results were discovered due to the culture of high tech companies. Investigating companies where every employee does not use a computer regularly to complete their job could yield different results.

Another area to look at for future research would be the internal social network platforms companies are creating for their employees to utilize. These are becoming an upcoming trend since use of social media is constantly growing. Companies want their employees to be social with each other, but sometimes only on company-based internal websites. These workplace social networks can give employees a chance to talk more openly about workplace-related experiences, while getting to know each other outside of the traditional work environment. 


\section{References}

1. A. P. McAfee, Enterprise 2.0: New collaborative tools for your organization's toughest challenges. (Boston, MA: Harvard Business School Press, 2009)

2. D. Love, 17 People who were fired for using Facebook. http://www.businessinsider.com/facebook-fired-2011-5 (2011)

3. D. A. Olson, J. Liu, K. S. Shultz, J. of Organizational Psychology, 12, 133 (2012)

4. P. Brandtzæg, M. Luders, J., Skjetne, International J. of Human-Computer Interaction, 26, 1006 (2010)

5. F. Xu, J. Shen, Chinese Education \& Society, 40, 86 (2007)

6. T. A. Judge, E. A. Locke, C. C. Durham, A. N. Kluger, J. of Applied Psychology, 83, 17 (1998)

7. N. Ichikura, S. Kumagai S, J. of Integrated Design \& Process Science, 14, 51 (2010)

8. K. Miller, Organizational communication: Approaches and processes. Belmont, CA: Wadsworth Publishing Company (2012)

9. J. A. Medved, Educational Leadership, 39, 555 (1982)

10. J. P. Boren, S. L. Johnson. Southern Communication J., 78, 128 (2013)

11. P. Malone, J. Hayes, Communication Studies, 63, 194 (2012)

12. B. J. Dik, R.D. Duffy. The Counseling Psychologist, 37, 424 (2009)

13. R. D. Duffy, W. E. Sedlacek, Career Development Quarterly, 59, 27 (2010)

14. R. D. Duffy, K. L. Autin, J. of Counseling Psychology, 60, 219 (2013)

15. M. F. Steger, B. J. Dik, In P. A. Linley, S. Harrington, N. Garcea (eds). Oxford handbook of positive psychology and work. Oxford: Oxford University Press, (2010)

16. A. Hirschi, J. of Counseling Psychology, 59, 479 (2012)

17. L. Browning, G. H. Morris, K. F. Kee, In K. S. Cameron, G. M. Spreitzer (eds), Oxford handbook of positive organizational scholarship. Oxford: Oxford University Press, (2012)

18. Facebook, Company Info at http://newsroom.fb.com/company-info (2015)

19. J. Raacke, J. Bonds-Raacke, Cyberpsychology \& Behavior, 11, 169 (2008)

20. X. Liu, R. LaRose, CyberPsychology \& Behavior, 11, 310 (2008)

21. K. Subrahmanyam, P. Greenfield, Future of Children, 18, 119 (2008)

22. E. Wenger, Communities of practice: Learning, meaning, and identity. New York, NY: Cambridge University Press (1999)

23. N. B. Ellison, C. Steinfield, C. Lampe. J. of Computer-Mediated Communication, 12, 1143 (2007)

24. S. Valenzuela, N. Park, K. F. Kee, J. of Computer-Mediated Communication, 14, (2009)

25. A. H. Brayfield, H. F. Rothe. J. of Applied Psychology, 35, 307 (1951)

26. R. D. Duffy, E. M. Bott, B. A. Allan, C. L. Torrey, B. J. Dik, J. of Counseling Psychology, 59, 50 (2012) 